\title{
Covid-19 and Exercise-Induced Immunomodulation
}

\author{
Carol Gois Leandro ${ }^{a}$ Wylla Tatiana Ferreira e Silva ${ }^{a}$ Adriano Eduardo Lima-Silva ${ }^{b}$ \\ a Laboratory of Physiology of Exercise - CAV - Federal University of Pernambuco, Recife, Brazil; \\ ${ }^{b}$ Human Performance Research Group, Federal University of Technology, Parana, Brazil
}

Severe acute respiratory syndrome coronavirus 2 (SARS-CoV-2), the virus that causes the novel coronavirus disease 2019 (COVID-19), has been responsible for a large global outbreak. The latest number of confirmed cases of COVID-19 is $>4.6$ million globally, including $>$ 315,000 confirmed deaths, and obliging $>4$ billion people to stay confined to their homes [1]. Most people with COVID-19 experience mild to moderate illness, but around $15 \%$ progress to severe pneumonia, and about $5 \%$ progress to acute respiratory distress syndrome. The maintenance of social distancing, frequent hand-washing, and avoiding touching the eyes, nose and mouth have been strongly advised by the WHO.

Reports from health authorities worldwide have converged for placing cities in lockdown, with no outdoor activities permitted including physical exercise. However, it is important to consider the benefits of regular exercise-induced immunomodulation as a potential means of taking precautions and also in clinical management. Indeed, sedentary behaviors such as watching TV, long periods of sitting, and the use of smartphones are associated with an increased risk of obesity, hypertension, and type 2 diabetes mellitus. This is an important topic for discus- sion, considering that, upon admission to hospital, most of the patients have presented with comorbidities like diabetes (10-20\%), hypertension (16.9\%), and other metabolic diseases including obesity and chronic inflammation (53.7\%) [2].

The immunopathology of the SARS-CoV-2 infection involves both the innate and adaptive immune system. After infection by the virus, there is an increase of neutrophil count and a decrease in the number of natural killer (NK) cells, and the advent of leukopenia based on the reduced percentage of monocytes, eosinophils, and basophils [3]. Regarding the adaptive immune response, a reduction in TCD4+ and TCD8+ lymphocytes has been observed. The upregulation of $\mathrm{B}$ lymphocytes induces the detection of high levels of IgG in the plasma 7-10 days after SARS-CoV-2 infection. In addition, there is an elevated production of proinflammatory cytokines including tumor-necrosis factor (TNF)- $\alpha$, interleukin (IL)-6, IL-1 $\beta$, IL-8, IL-17, and IL-2 [4]. The abnormal elevated concentrations of these cytokines leads to crosstalk activation of the neuroendocrine-immune system, with a consequent release of glucocorticoids which can impair the immune response [5]. The abnormally elevated re-

\section{KARGER}

(c) 2020 S. Karger AG, Basel

karger@karger.com

www.karger.com/nim
Carol Góis Leandro

Universidade Federal de Pernambuco

Centro Acadêmico de Vitória - CAV

Recife (Brazil)

carol.leandro@ufpe.br 
lease of cytokines can induce multiple organ failure, involving the heart, liver, kidney, and lungs. Particularly in the lungs, the cytokine-induced infiltration of neutrophils and macrophages can provoke the formation of hyaline membranes and fracture of the alveolar wall [4].

Exercise-induced immunomodulation has been recognized for $>3$ decades, with around 5,000 peer-reviewed original and review papers available in the MEDLINE and PubMed databases. Exercise-induced immunomodulation seems to be dependent on the interplay of the intensity, duration, and frequency of exercise [6]. In both human and animal models, exercise of long duration and/or intense exercise ( $>2 \mathrm{~h}$ and/or $>80 \%$ of maximal oxygen uptake, $\mathrm{VO}_{2 \max }$ ) is associated with markers of immunosuppression such as: (1) increased production of proinflammatory cytokines (IL-6, IL-8, TNF- $\alpha$, and IL-1) [7]; (2) an increase in lower respiratory tract infections [8]; (3) reduced activity of NK cells, T and B lymphocytes, and neutrophils; (4) reduced production of salivary IgA and plasma IgM and IgG; and (5) a low expression of major histocompatibility complex II (MHC II) in macrophages $[9,10]$. These changes can be detected hours to days after the end of a prolonged and/or intense bout of endurance exercise. In addition, the hormones of the hypothalamicpituitary-adrenal axis, glucocorticoid receptors, and intracellular NF- $\kappa \mathrm{B}$ signaling seem to be involved in chronic inflammatory airway disease; all of these are increased after prolonged/intense exercise [6]. Thus, long-duration and/or intense exercise may make humans more susceptible to infection (mainly upper respiratory tract infections) which can increase the risk of infection and aggravation by COVID-19.

Conversely, clinical and translational studies on humans have demonstrated that regular bouts of short-lasting (i.e., 45-60 $\mathrm{min}$ ), moderate-intensity exercise (50$\left.70 \% \mathrm{VO}_{2 \max }\right)$, performed at least 3 times a week is beneficial for the host immune defense, particularly in older adults and people with chronic diseases [6]. Moderateintensity exercise seems to be associated with increased leukocyte function in humans [11], and has been found to enhance chemotaxis, degranulation, cytotoxic activity, phagocytosis, and the oxidative activity of neutrophils and macrophages in rats [12]. Increased cytolytic activity of NK cells and NK cell-activating lymphokine (LAK) during a 60 -min of moderate-intensity exercise by healthy cyclists was also reported [11]. Thus, contrary to longduration/intense exercise, moderate-intensity exercise may contribute to increased immune protection. Whether or not individuals habituated to practicing moderateintensity exercise experience less serious complications associated with COVID-19 deserves further investigation.

COVID-19 cases have been reported in certain populations like elderly people, children/adolescents, and pregnant women. The older population is more susceptible to infection in general and has also been identified as being particularly vulnerable during the current outbreak. It has been demonstrated that regular, moderate exercise by older adults reduces concentrations of proinflammatory cytokines (IL-6, TNF- $\alpha$, and IL- $1 \beta$ ), increases NK cell and TCD8+ cell cytotoxic activity, and enhances neutrophil function and B lymphocyte proliferation [13]. Although the reported number of cases of COVID-19 in children/adolescents is relatively low, it is important to note that chronic moderate/intense exercise and/or exercise training in healthy children and adolescents are associated with a reduction in the incidence of infection and a faster recovery of the immune system [6]. In pregnant women with COVID-19, fetal distress and preterm delivery have been seen in some cases, but no evidence of in utero transmission has been observed [14].

Physical exercise concurrent with exercise training (aerobic-resistance training) seems to enhance macrophage phagocytosis and oxidative burst, neutrophil oxidative burst, increase the percentage of TCD4 lymphocytes, and reduce circulating TNF- $\alpha$ and IL- 6 , followed by an increase in IL-1 $\beta$ [6]. Whether such exercise-induced alterations in the immune system would be protective against SARS-CoV-2 infection in these populations is unknown and further studies will be necessary. However, it is interesting to consider that exercise could play a role in counteracting the negative effects of isolation and confinement stress on immune competency in this population.

Clinically, the first phase of immune response induced by SARS-CoV-2 infection is a specific adaptive immune response to eliminate the virus and prevent disease progression. Patients with severe complications derived from COVID-19 infection present with lymphocytopenia and a cytokine release syndrome mediated by leukocytes other than T cells. This is important because the reduction of IL- 6 and TNF- $\alpha$ increases the release of anti-inflammatory cytokines. Anti-inflammatory cytokines can suppress a hyperactive immune response, promoting tissue repair, especially for lung damage [3]. Interestingly, there is an increase in the expression of proinflammatory cytokines in skeletal muscle (TNF- $\alpha$ and IL-1 $\beta$ ) during moderateintensity exercise, but there is no alteration in the circulating of these cytokines [15]. In contrast, there is a noticeable increase in the circulating concentrations of the
Neuroimmunomodulation 2020;27:75-77 DOI: $10.1159 / 000508951$
Leandro/Ferreira e Silva/Lima-Silva 
anti-inflammatory cytokines IL-1 receptor antagonist (IL-1ra) and IL-10 [15]. Low-to-moderate intensity exercise $\left(30-60 \% \mathrm{VO}_{2 \max }\right)$ also increases the production of anti-inflammatory cytokines (IL-4 and IL-10) by T cells. Thus, regular moderate-intensity exercise may be effective in enhancing an anti-inflammatory response, which could help to revert lymphocytopenia in COVID-19 patients. Further experimental studies will be necessary to confirm or refute this hypothesis.

In conclusion, the pandemic of COVID-19 has become a clinical threat worldwide, for physicians, researchers, nurses, healthcare workers, and mostly the general population. There is consensus that the way to reduce the rate of contamination and spread of SARS-CoV-2 via human-to-human transmission is social distancing. However, the practice of moderate-intensity exercise at home is recommended. Low-to-moderate exercise-induced im- munomodulation might be an important tool to improve immune responses against the progression of SARSCoV-2 infection.

\section{Disclosure Statement}

The authors have nothing to disclose.

\section{Funding Sources}

There was no funding.

\section{Author Contributions}

All authors contributed equally.

\section{References}

1 World Health Organization. [Internet] Novel coronavirus (COVID-19) situation. Available from: https://covid19.who.int/. 2020.

2 Guan WJ, Liang WH, Zhao Y, Liang HR, Chen ZS, Li YM, et al.; China Medical Treatment Expert Group for COVID-19. Comorbidity and its impact on 1590 patients with COVID-19 in China: a nationwide analysis. Eur Respir J. 2020 May;55(5):2000547.

3 Cao X. COVID-19: immunopathology and its implications for therapy. Nat Rev Immunol. 2020 May;20(5):269-70.

4 Sarzi-Puttini P, Giorgi V, Sirotti S, Marotto D, Ardizzone S, Rizzardini G, et al. COVID-19, cytokines and immunosuppression: what can we learn from severe acute respiratory syndrome? Clin Exp Rheumatol. 2020 Mar-Apr; 38(2):337-42.

5 Mehta P, McAuley DF, Brown M, Sanchez E, Tattersall RS, Manson JJ; HLH Across Speciality Collaboration, UK. COVID-19: consider cytokine storm syndromes and immunosuppression. Lancet. 2020 Mar;395(10229):1033-4.

6 Simpson RJ, Campbell JP, Gleeson M, Krüger K, Nieman DC, Pyne DB, et al. Can exercise affect immune function to increase susceptibility to infection? Exerc Immunol Rev. 2020;26:8-22.
7 Ferreira GA, Felippe LC, Bertuzzi R, Bishop DJ, Barreto E, De-Oliveira FR, et al. The Effects of Acute and Chronic Sprint-Interval Training on Cytokine Responses Are Independent of Prior Caffeine Intake. Front Physiol. 2018 Jun;9:671.

8 Cantó E, Roca E, Perea L, Rodrigo-Troyano A, Suarez-Cuartin G, Giner J, et al. Salivary immunity and lower respiratory tract infections in non-elite marathon runners. PLOS One. 2018 Nov; 13(11):e0206059.

9 Leandro CG, Martins de Lima T, Folador A, Alba-Loreiro T, do Nascimento E, Manhães de Castro R, et al. Physical training attenuates the stress-induced changes in rat T-lymphocyte function. Neuroimmunomodulation. 2006;13(2):105-13.

10 Leandro CG, de Lima TM, Alba-Loureiro TC, do Nascimento E, Manhães de Castro R, de Castro CM, et al. Stress-induced downregulation of macrophage phagocytic function is attenuated by exercise training in rats. Neuroimmunomodulation. 2007; 14(1):4-7.
11 Bigley AB, Rezvani K, Pistillo M, Reed J, Agha $\mathrm{N}$, Kunz H, et al. Acute exercise preferentially redeploys NK-cells with a highly differentiated phenotype and augments cytotoxicity against lymphoma and multiple myeloma target cells. Part II: impact of latent cytomegalovirus infection and catecholamine sensitivity. Brain Behav Immun. 2015 Oct;49:59-65.

12 Senna SM, Torres MK, Lopes DA, AlheirosLira MC, de Moura DB, Pereira VR, et al. Moderate physical training attenuates perinatal low-protein-induced spleen lymphocyte apoptosis in endotoxemic adult offspring rats. Eur J Nutr. 2016 Apr;55(3):1113-22.

13 Sellami M, Gasmi M, Denham J, Hayes LD, Stratton D, Padulo J, et al. Effects of Acute and Chronic Exercise on Immunological Parameters in the Elderly Aged: Can Physical Activity Counteract the Effects of Aging? Front Immunol. 2018 Oct; 9:2187.

14 Rasmussen SA, Smulian JC, Lednicky JA, Wen TS, Jamieson DJ. Coronavirus Disease 2019 (COVID-19) and pregnancy: what obstetricians need to know. Am J Obstet Gynecol. 2020 May;222(5):415-26.

15 Peake JM, Della Gatta P, Suzuki K, Nieman DC. Cytokine expression and secretion by skeletal muscle cells: regulatory mechanisms and exercise effects. Exerc Immunol Rev. 2015;21:8-25. 